\title{
Lactic dehydrogenase isoenzymes in normal and pathological spinal fluids
}

\author{
V. R. CUNNINGHAM, J. PHILlips, AND E. J. FIELD \\ From the Medical Research Council Demyelinating Disease Research Unit, \\ University of Newcastle upon Tyne
}

SYNOPSIS Spinal fluid lactate dehydrogenase (L.D.H.) isoenzyme patterns have been investigated in normal subjects, in those with non-destructive nervous disease, and in those with destructive lesions in the nervous system.

The spinal fluid from organic disease in general showed a significantly increased level of L.D.H.2 and L.D.H..$_{3}$ so that the combined values of L.D.H.2 and L.D.H.3 might perhaps be of value in determining the presence of destructive nervous lesions.

The high resolution of protein bands obtainable by electrophoresis of native spinal fluid on polyacrylamide gel (Cunningham, 1964) has been used to investigate changes in the lactate dehydrogenase system reported by Lowenthal, van Sande, and Karcher (1961) in health and neurological disease. Not unexpectedly, the high sensitivity of the method has uncovered individual variations, the full appreciation of which will require considerable further investigation.

\section{MATERIAL AND METHODS}

Blood serum was used as soon after collection as possible, though substantially similar results were obtained after storage at $-60^{\circ} \mathrm{C}$. for up to four months. Specimens of spinal fluid used were absolutely clear and had a cell count of less than 3 cells $/ \mathrm{ml}$. Only one specimen of spinal fluid from a normal subject was available but those from patients without evidence of organic disease of the nervous system involving tissue destruction were accepted as 'normal', e.g., idiopathic epilepsy, neurosis, headaches. The spinal fluids were stored at $-20^{\circ} \mathrm{C}$. for not longer than one week before use and usually for less than 48 hours, since preliminary experiments using both the total assay technique and the visualization of the isoenzymes after electrophoresis showed that lactic dehydrogenase was very labile. Marked reduction in enzyme activity, particularly in the globulin region, was apparent in spinal fluids stored for more than four weeks at $-20^{\circ} \mathrm{C}$.

DISC ELECTROPHORESIS Electrophoresis was carried out by the method of Cunningham (1964) on polyacrylamide gel. In this investigation, however, sucrose was omitted and the sample placed directly on top of the spacer gel,

Received for publication 14 July 1965. followed by careful layering of the tris-glycine buffer into the gel tube $(6 \mathrm{~mm}$. bore) until contact was made with buffer in the cathode compartment. Electrophoresis was continued at $4 \mathrm{~mA}$ per specimen until the markers showed adequate separation (usually about three hours).

Samples of spinal fluid containing 3,6, 12, and 24 units of L.D.H. activity (see below) were run simultaneously and the isoenzymes visualized by direct staining with MTT according to the method of Latner and Skillen (1961).

The reaction was stopped after 35 minutes at $37^{\circ} \mathrm{C}$. The purple formazan dye showed maximal absorption at $489 \mathrm{~m} \mu$. Gels were placed in precision bore tubing and scanned on a Chromoscan densitometer (Joyce-Loebl) using an Ilford no. 58 filter. For serum analysis, electrophoresis tubes were completely filled with buffer followed by the addition of 0.03 to $0.06 \mathrm{ml}$. serum at the small pore-buffer interface by means of a micrometer pipette; otherwise conditions were unchanged.

TOTAL L.D.H. ACTIVITY This was determined by a modification of the spectrophotometric method of Wroblewski and La Due (1955) at $27^{\circ} \mathrm{C}$. using a mixture comprising:-

Phosphate buffer $p \mathrm{H} 7 \cdot 2 \ldots 1 \cdot 5 \mathrm{ml} .(0 \cdot 12 \mathrm{M})$

Sodium pyruvate ...... $0.1 \mathrm{ml} .(2.5 \mathrm{mg} . / \mathrm{ml}$.)

D.P.N.H. $\quad \ldots \ldots \ldots \ldots .0 .1 \mathrm{ml} .(2.0 \mathrm{mg} . / \mathrm{ml}$. water

Cerebrospinal fluid $\ldots . .0 .5 \mathrm{ml}$. pH 9.0 with $\mathrm{NaOH}$ )

One unit of activity was defined as a decrease in optical density at $340 \mathrm{~m} \mu$ of 0.001 for $1 \mathrm{ml}$. of specimen per minute.

In order to obtain a more accurate assay of L.D.H. activity in those samples where the activity was found to be 20 units, the spinal fluid concentration was doubled and buffer volume correspondingly reduced. Control experiments on spinal fluids, with activities in the 0-50 unit range, showed that, for any specimen, there was a linear relationship between concentration of L.D.H. and 
rate of decrease in optical density. For purposes of comparison serum determinations were carried out on 18 normal people, using $0.1 \mathrm{ml}$. serum and $2.0 \mathrm{ml}$. of $0 \cdot 1$ phosphate buffer.

Altogether 22 cases without structural damage in the nervous system were examined (normal, neurosis, headaches, idiopathic epilepsy); 31 cases with structural damage (head injury, cerebrovascular disease, hydrocephalus, cerebral tumour, pre-senile dementia) and four acute and four chronic cases of multiple sclerosis.

\section{RESULTS}

Preliminary experiments were directed to the identification of L.D.H. bands in serum. Normal serum invariably showed five main bands (Fig. 1) when the serum volume was $0.03 \mathrm{ml}$. However, if the volume of the sample was increased above this amount then several minor bands made their appearance and especially a band between L.D.H. 3 and 4 . It was observed that, as the serum volume was increased, the band (3a) between 3 and 4 increased in intensity whilst band 4 decreased (see Fig. 2). This observation was repeatedly confirmed and raises doubt as to the validity of this technique for quantitative determination of isoenzymes at serum levels greater than $0.03 \mathrm{ml}$.

As a standard, L.D.H.1-5 from human liver was obtained by starch gel electrophoresis by the method of Ressler, Schultz, and Joseph (1963a, b). The positions of the enzyme fractions were determined by examination of longitudinal gel strips from both sides of the plate. The relevant gel areas containing L.D.H.1-5 isoenzymes were frozen and thawed to extract the enzymes and the fluid phases re-run by the polyacrylamide technique. It was thus possible to establish that L.D.H. ${ }_{1}$ was solely isoenzyme 1; L.D.H.. , isoenzyme 2; L.D.H. 3 isoenzyme 3; and L.D.H.4 was isoenzyme 4. However, when L.D.H. ${ }_{5}$ was run on polyacrylamide gel, it appeared that it had been separated further into several bands in the region bounded by the cathode end of the small-pore gel and the isoenzyme 4 band.

This was confirmed by (a) subjecting pure $\frac{\bar{C}}{\sigma}$ crystalline L.D.H.5 from rabbit muscle ${ }^{1}$ to disc $\frac{\overline{\bar{\rho}}}{\overline{1}}$ electrophoresis. At least four isoenzymes were $\mathbb{\otimes}$ visualized, including L.D.H.4, in the $\gamma$-globulin region. In addition, small bands of L.D.H. activity ${ }^{\infty}$ which coincided with L.D.H.1 and L.D.H.2 positions $\vec{\circ}$ of normal rabbit sera (Fig. 3) were observed. The rabbit muscle enzyme preparation was fractionated ${ }^{\omega}$ on starch gel (Latner and Skillen, 1961) and showed L.D.H. ${ }_{5}$ but no conclusion could be drawn regarding the presence of L.D.H.4 ; and (b) samples of sera from patients suffering from liver damage were run on starch gel electrophoresis to confirm an elevated $\delta$ L.D.H..$_{5}$ isoenzyme. Then $0.03 \mathrm{ml}$. was run ono acrylamide and several bands were detected in the $\gamma$-globulin region (Fig. 4). Attempts to clarify the $z$ position of L.D.H..$_{5}$ by heating human serum to $57^{\circ} \mathrm{C}$. under controlled conditions according to the $\frac{\Phi}{3}$ method of Wroblewski and Gregory (1961) were not conclusive, since the activities of L.D.H..$_{3}$ as well as the enzymes in the $\gamma$-globulin region were $\vec{\theta}$ significantly decreased (Fig. 5).

In normal serum, band 2 was consistently the greatest and band 5 the least. L.D.H.4 showed no tendency to split.

NORMAL SPINAL FLUID Normal serum and spinal fluid were run simultaneously with bromophenol blue as a marker, and the relative mobilities of the enzyme bands (Table I) suggest that isoenzymes L.D.H.1-5 ${ }_{1-5}$ also occur in cerebrospinal fluid. When increasing quantities of normal spinal fluid were fractionated, however, additional isoenzymes were? observed until at about 100 units of activity at least $\frac{0}{3}$ 18 L.D.H. isoenzymes were present, including six

${ }^{1}$ Boehringer \& Co., Ltd., W. Germany.

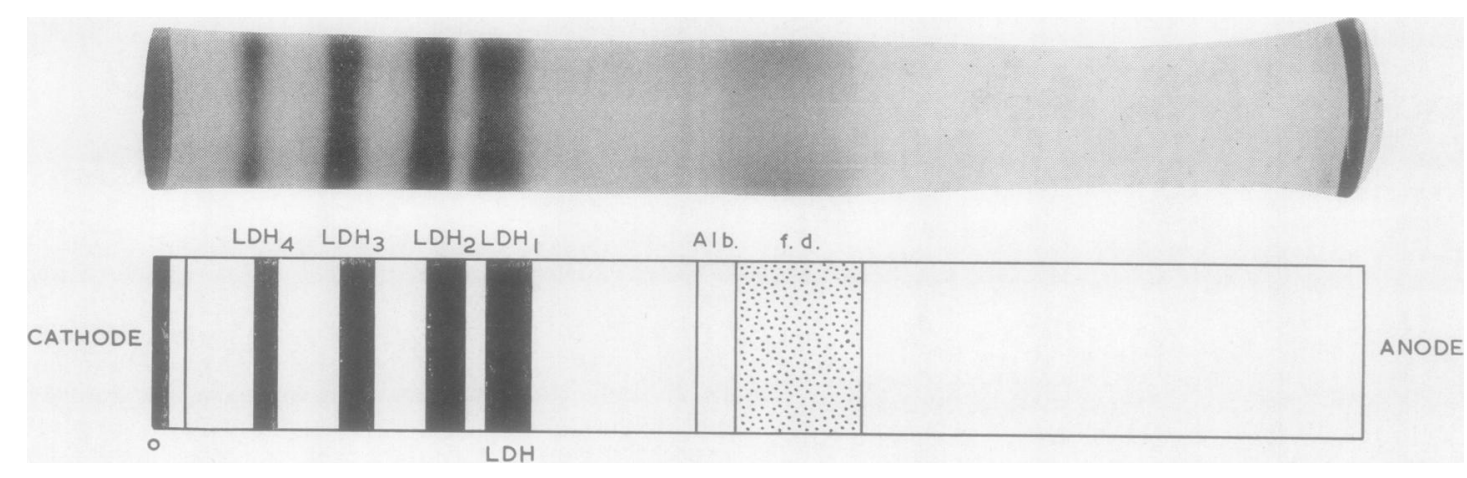

FIG. 1. Lactic dehydrogenase enzymes of normal human serum $(0.03 \mathrm{ml}$.$) . f.d. =$ free dye. 


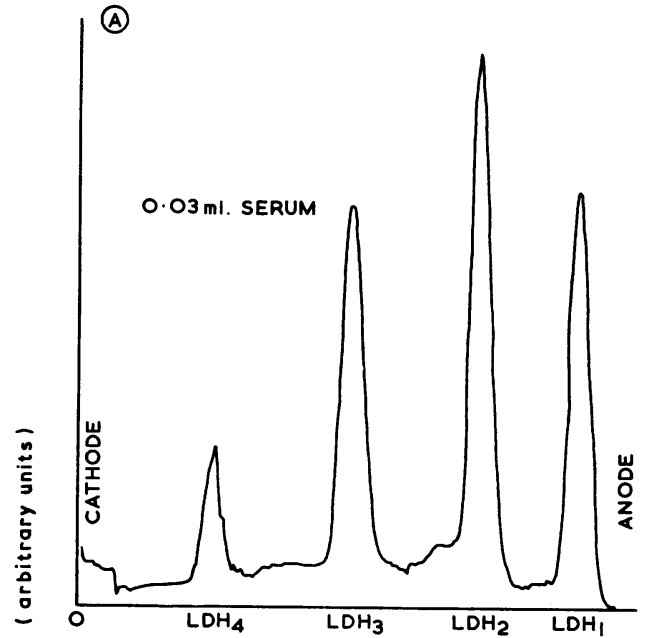

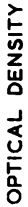

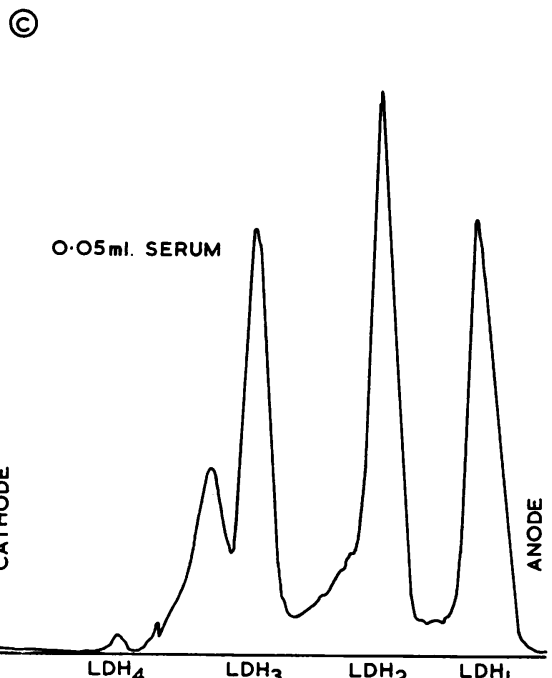

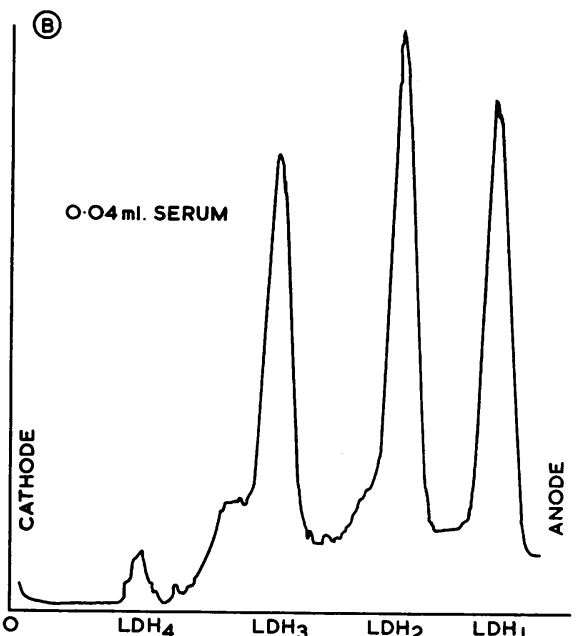

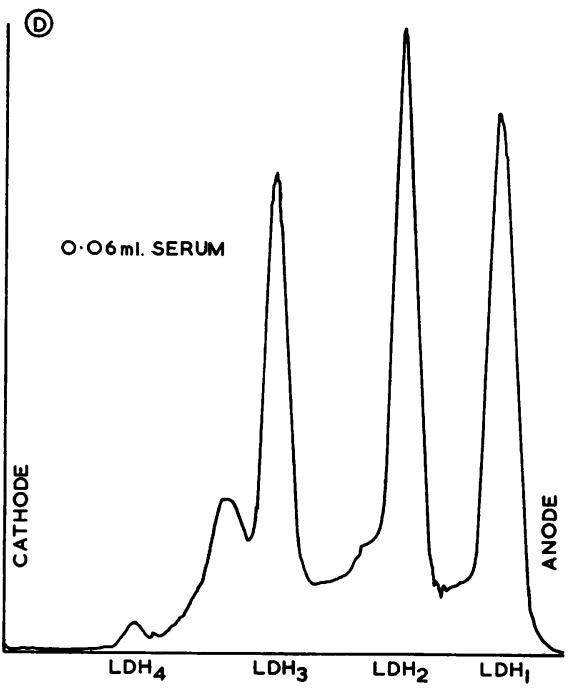

FIG. 2. Variation in lactic dehydrogenase distribution using increasing amounts of human serum:

(a) $0.03 \mathrm{ml}$. serum; (b) $0.04 \mathrm{ml}$. serum; (c) $0.05 \mathrm{ml}$. serum; (d) $0.06 \mathrm{ml}$. serum. Note the progressive appearance of $a$ band between the initial LDH 3 and 4, and simultaneous decrease in LDH 4.

\section{TABLE I}

RELATIVE MOBILITIES ${ }^{1}$ OF THE LACTIC DEHYDROGENASE ISOENZYMES OF NORMAL SERUM AND CEREBROSPINAL FLUID IN ACRYLAMIDE GEL AT $p H \mathbf{8 . 9}$

Specimen L.D.H. Isoenzymes L.D.H., L.D.H.2 L.D.H.3 L.D.H., L.D.H.

\begin{tabular}{llllll}
\hline Serum 0.80 & 0.62 & 0.43 & 0.22 & $0-0.20$ & 1.18 \\
$\begin{array}{l}\text { Cerebrospinal } \\
\text { fluid }\end{array}{ }^{0.79}$ & 0.06 & 0.42 & 0.2 & $0-0.18$ & 1.10 \\
'Albumin $=1.0$ & & & & &
\end{tabular}

isoenzymes in the $\gamma$-globulin region and three between L.D.H. ${ }_{1}$ and the albumin fraction. For routine work, fluid up to $1.5 \mathrm{ml}$. was successfully fractionated. With normal sera, the same number of bands were seen but since the enzyme activity/protein content of the spinal fluid is about thrice that of serum the spinal fluid patterns were much easier to obtain.

At levels up to 24 units, normal spinal fluid showed three bands which were designated L.D.H.1-3 on the basis of their relative mobilities as compared with the serum isoenzymes. Because of the difficulties posed by the presence of both strong and weak bands in the same gel, and also the problem raised by the apparent inter-relationship of the serum isoenzymes in the $\gamma$-globulin region of the gel, 
(A)

CATHODE
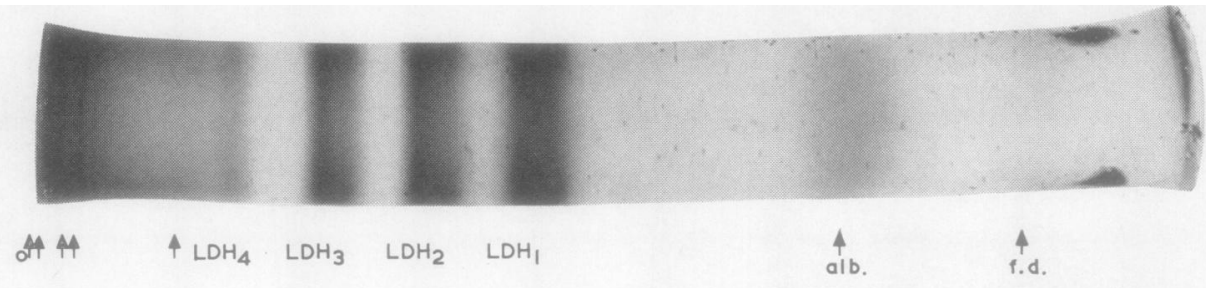

(B)

CATHODE
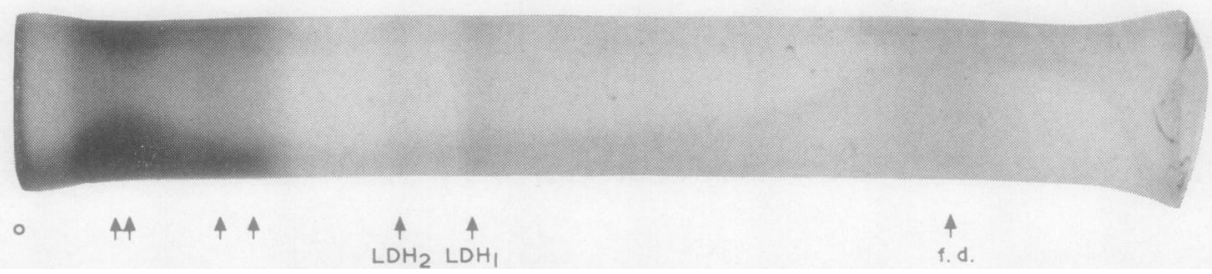

FIG. 3. A $0.03 \mathrm{ml}$. normal rabbit serum.

$B \quad L D H 5$, crystalline rabbit muscle enzyme.

Note the presence of $\mathrm{LDH}_{1}, \mathrm{LDH}_{2}$, and multiple bands in the $\gamma$-globulin region.

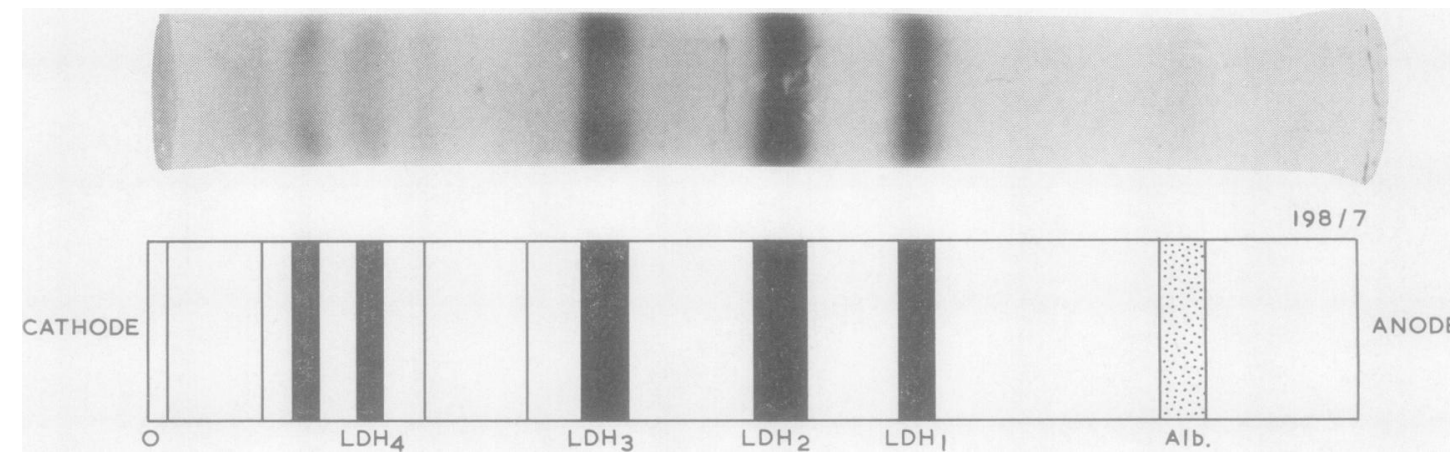

FIG. 4. Lactic dehydrogenase isoenzymes in serum from a jaundiced patient $(0.03 \mathrm{ml}$.$) .$

Note the presence of additional bands in the $\gamma$-globulin region.

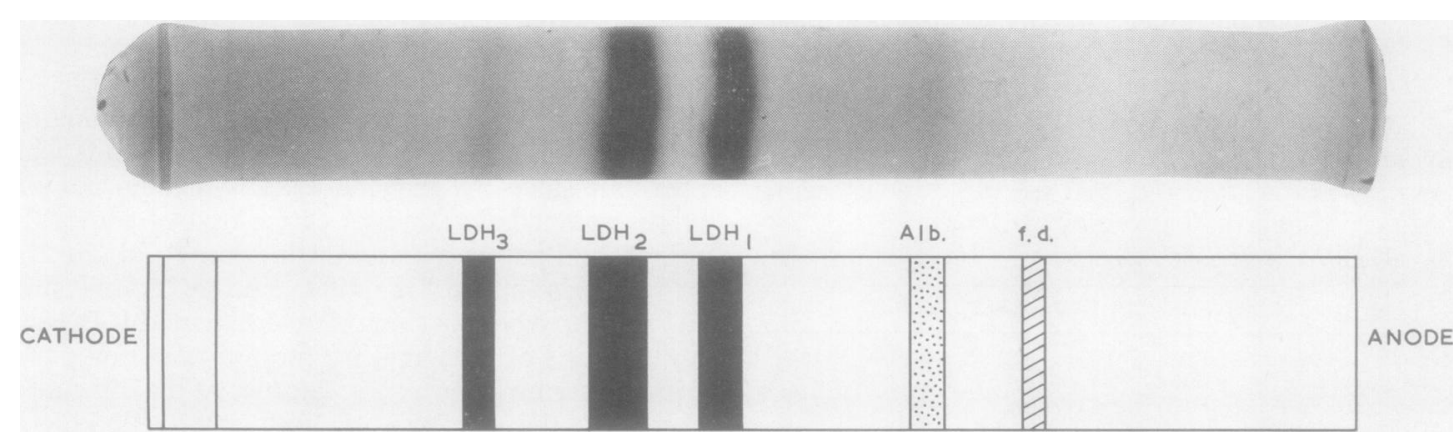

FIG. 5. Normal human serum heated to inactivate $\mathrm{LDH}_{5}$. Note the reduction in activity of $\mathrm{LDH}_{3}$ as well as the isoenzymes $\widetilde{\mathbb{Q}}$ in the $\gamma$-globulin region. 
quantitative work was limited to the L.D.H. L.D.H.2, and L.D.H. ${ }_{\cdot 3}$ isoenzymes of spinal fluid.

At total levels of L.D.H. activity from 3 to 24 units, L.D.H.1, 2, 3, were always demonstrable, though at the 3 unit level, L.D.H.. was often weak. The ratios of the individual L.D.H.1, L.D.H.2, and L.D.H. ${ }_{3}$, when $3,6,12$, and 24 units were analysed, were determined and found to be fairly constant over the range 6-24 units (Table II).

\section{TABLE II}

EFFECT OF VARIATION OF L.D.H. CONCENTRATION ON THE RATIOS OF THE ISOENZYMES OF SPINAL FLUID

\begin{tabular}{lcccc}
$\begin{array}{l}\text { Volume of Cerebrospinal } \\
\text { Fluid }(\mathrm{ml} .)\end{array}$ & $\begin{array}{c}\text { L.D.H. } \\
\text { Total Units }\end{array}$ & \multicolumn{2}{l}{ L.D.H. Isoenzymes } \\
\cline { 3 - 5 } & & L.D.H.1 & L.D.H.2 & L.D.H.3 \\
\hline 0.09 & 3 & 100 & 48 & 44 \\
0.18 & 6 & 100 & 50 & 46 \\
0.36 & 12 & 100 & 56 & 50 \\
0.72 & 24 & 100 & 54 & 54
\end{tabular}

'Normal' spinal fluid from a case of renal hypertension.

Pathological SPINAL FLuid The spinal fluids submitted to analysis are set out in Table III. (Detailed protocols are too lengthy for publication but will be sent on request.) Variation in absolute L.D.H. levels was very great, as other workers have also found. For simplicity, average values have been calculated. It will be seen that, in general, L.D.H. activity is raised in the presence of organic structural disease of the nervous system, as compared with the epilepsy, neurosis, etc., group in which the absence of significant structural change may be presumed.

Because of the small number of cases in each of the pathological categories, all cases with presumed structural damage were taken together and compared with the group without structural change. Analysis showed that both L.D.H.. and L.D.H.3 were significantly increased in the organic as compared
TABLE III

SPINAL FLUID

No. of L.D.H.

Cases (units)

\begin{tabular}{lll} 
Ratio & \\
\hline I & II & III
\end{tabular}

No structural damage

Structural damage

(other than multiple

sclerosis)

Multiple sclerosis

(acute)

Multiple sclerosis

(chronic)

${ }^{1} P=0.01-0.005$

${ }^{2} \mathbf{P}<0.001$

$\begin{array}{lllll}22 & 23 \cdot 3(8-50) & 100 & 58 \cdot 1^{1} & 29 \cdot 7^{2} \\ 31 & 39 \cdot 0(8-88) & 100 & 82 \cdot 3^{1} & 56 \cdot 8^{2} \\ 4 & 32 \cdot 5(26-29) & & 86 \cdot 0 & 31 \cdot 0 \\ 4 & 43 \cdot 7(7-99) & & 87 \cdot 3 & 57 \cdot 3\end{array}$

with the non-organic group $(P=0.01-0.005$ and $<0 \cdot$ C01 respectively).

During the fractionation of many samples of spinal fluid, two features were observed which merit further consideration. A zone of intense staining invariably occurred on the anodic side of the free dye, i.e., faster than the dye, but on examination was found to be non-lactate dependent (Fig. 6). It would appear to be due to non-enzymatic reduction of MMTsimilar to that reported by Barnett (1964) who observed this phenomenon in the serum albumin fraction using cellulose acetate electrophoresis. In addition, on conclusion of electrophoresis, but before the addition of the enzyme substrate, $20 \%$ of spinal fluid specimens showed the presence of a secondary blue band in the region between albumin and free dye.

\section{DISCUSSION}

Studies of spinal fluid L.D.H. so far reported have given inconsistent results with little apparent relevance as an aid in diagnosis (Green, Oldewurtel, O'Doherty, and Forster, 1958; Lowenthal et al., 1961 ; van der Helm, Zondag, and Klein, 1963; van

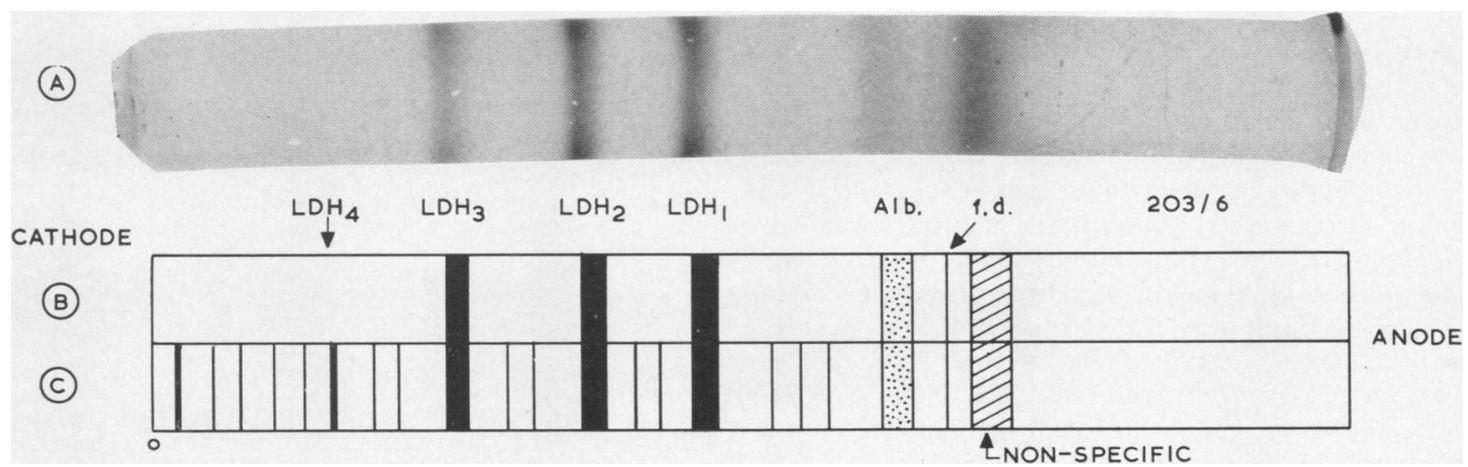

FIGS. 6a and b. The LDH isoenzymes of normal spinal fluid (12 units). Note region of non-specific activity preceding the free dye (f.d.). c. LDH isoenzymes of same spinal fluid (100 units). 
Rymenant and Otten, 1963). Van der Helm et al. comment that 'from a quantitative point of view ... experiments were not very reproducible.' Our own experience has shown that the profile obtained may be misleading if insufficient L.D.H. is applied to the polyacrylamide. Preliminary experiments were therefore undertaken at $3,6,12$, and 24 units level, and these showed that when the latter amounts were used, substantially the same quantitative picture emerged. For normal spinal fluids, even at the lowest enzyme level, L.D.H.1, 2,3 , were above the limit at which they could be detected and their ratios were found to be constant over the range 6-24 units. This suggested that the saturation point of even the most active isoenzyme (L.D.H. . ) had not been reached. If over 24 units were applied discrepancies appeared because of possible saturations of various bands and these would tend to obliterate observable differences. Therefore, in all analyses, all four levels were used. In practice the average values for the individual isoenzyme at 6 units and 12 units level was regarded as a fair measure of each band.

Whilst most workers (e.g., Lowenthal et al., 1961; van der Helm et al., 1963) have described five major bands in spinal fluid, the emergence of so many fractions in the $\gamma$-globulin region limited the possibility of quantitative analysis to the three most prominent bands, L.D.H.1-3. It must be noted, however, that in our polyacrylamide system at least 18 isoenzymes were visible under good experimental conditions, six of which were in the region where L.D.H. ${ }_{4}$ and L.D.H..$_{5}$ of other authors are located. Whilst an additional experiment has enabled us to locate L.D.H.4, there is still no certainty as to which is band 5. It is also possible that L.D.H.5 has been fractionated by our method because of the greater resolving power of acrylamide as compared with starch and agar. Moreover, the clear background of polyacrylamide enables visualization of faint bands which might be obscured in starch gel. For example, the presence of L.D.H.1, L.D.H.2, and multiple bands in the region of the crystalline rabbit muscle enzyme were easily demonstrable. In addition, our buffer may be a contributory factor in that the glycine component could act as a sequestering agent of this metallo-enzyme (Vallee and Wacker, 1956).

Our direct spectrophotometric method, based on the formation of an insoluble blue formazen for quantitative analysis of the three strongest bands L.D.H. ${ }_{1-3}$, minimizes the risk of fallacious results such as those described by Wieme, van Sande, Karcher, Lowenthal, and van der Helm (1962), especially as enzyme levels of $3,6,12$, and 25 units were used for each specimen.
The relative increase of isoenzymes II and III in pathological spinal fluids could, on the basis of the $\overrightarrow{=}$ present findings, be equally well derived from brainor from serum, and the present work offers no등 evidence either way. In this connexion it may be $\bar{c}$ noted that whilst Lowenthal et al. (1961) found $a_{\mathbb{\infty}}$ simultaneous increase in L.D.H. fraction in serum and spinal fluid, van der Helm et al. (1963) found now association between them and were unable to $\vec{\circ}$ suggest how far brain tissue could contribute to normal or abnormal L.D.H. activity in spinal fluid. $\bar{\omega}$

Delank (1963) has recently claimed that a very응 low total L.D.H. content of spinal fluid was an? exclusive characteristic of multiple sclerosis. This $\overrightarrow{0}$ finding is not in accordance with the report by Fleisher, Wakim, and Goldstein (1957), who found no change in multiple sclerosis, but is supported by Spolter and Thompson (1962) who claimed $\mathrm{a}^{\circ}$ significantly lower L.D.H. level in this disease than in control subjects. Our own small series has showno L.D.H. values ranging from 7 to 99 units and $\stackrel{\Phi}{7}$ analysis of the L.D.H. in these cases suggests that bands II and III are differentially and markedly raised though the number of cases is too small for $\vec{\bullet}$ statistical significance. Lowenthal et al. (1961) found $\leftrightarrow$ no specific changes in enzyme pattern in the different neurological diseases they investigated.

We would like to thank Dr. Gryspeerdt of the Newcastle⿳亠二口犬 General Hospital, and Prof. Henry Miller, Department of Neurology, Royal Victoria Infirmary, Newcastle on $\stackrel{\mathbb{Q}}{\circ}$ Tyne, for the specimens of spinal fluid and sera; Mr. $\Rightarrow$ Layfield of the Department of Photography, University of Newcastle on Tyne, for the photographs; and Dr. A. Skillen for the starch gel electrophoresis.

\section{REFERENCES}

Barnett, H. (1964). J. clin. Path., 17, 567.

Cunningham, V. R. (1964). Ibid., 17, 143.

Delank, H. W. (1963). Dtsch. Z. Nervenheilk., 184, 632.

Fleisher, G. A. Wakim, K. G., and Goldstein, N. P. (1957). Proc. Mayo Clin., 32, 188.

Green, J. B., Oldewurtel, H. A., O'Doherty, D. S., and Forster, F. M. (1958). Arch. Neurol. Psychiat. (Chic.), 80, 148.

Latner, A. L., and Skillen, A. W. (1961). Lancet, 2, 1286.

Lowenthal, A., van Sande, M., and Karcher, D. (1961). J. Neuro- $D$ chem., 7, 135.

Spolter, H., and Thompson, H. G. Jr. (1962). Neurology (Minneap.), 12, 53.

Ressler, N., Schultz, J. L., and Joseph, R. R. (1963a). Nature (Lond.), హ 197, 872.

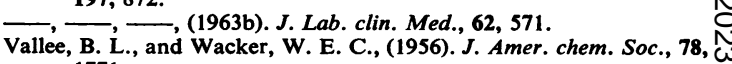
1771 .

van der Helm, H. J., Zondag, H. A., and Klein, F. (1963). Clin. chim.

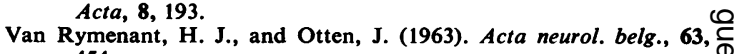

Wroblewski, F., and Gregory, K. F. (1961). Ann. N.Y. Acad. Sci., 94, 912.

-, and La Due, J. S. (1955). Proc. Soc. exp. Biol. (N. Y.), 90, 210.

Wieme, R. J., van Sande, M., Karcher, D., Lowenthal, A., and van $\frac{O}{(D)}$ der Helm, H. J. (1962). Clin. chim. Acta, 7, 750. 